\title{
Test Article Physical Class
}

National Cancer Institute

\section{Source}

National Cancer Institute. Test Article Physical Class. NCI Thesaurus. Code C154896.

The physicochemical category that a test article belongs to based on the composition and properties of that article. 